\title{
Problems of the Chinese language textbook content in teaching future teachers of Chinese
}

\author{
Anzhela Anatolievna Kazantseva ${ }^{1,}$, Yulia Borisovna. Dyundik ${ }^{2}$, Elena Yurievna Sizykh ${ }^{3}$, \\ Anastasiia Aleksandrovna Kazantseva ${ }^{4}$ \\ ${ }^{1}$ Moscow City University, Moscow, Russia \\ ${ }^{2}$ Irkutsk State University, Irkutsk, Russia \\ ${ }^{3}$ Saint Petersburg State University of Economics, Saint Petersburg, Russia \\ ${ }^{4}$ Moscow City University, Moscow, Russia
}

\begin{abstract}
The present paper suggests the idea of development and introduction of a textbook in the Chinese language for future teachers of Chinese in the system of higher education in Russia. The authors analyze a number of reasons for the absence of such textbook in our education system. They consider both formal and content criteria of the existing textbooks for teaching practical Chinese language at the initial stage, which are most frequently used at our educational institutions. Special attention is paid to their advantages and disadvantages as well as to compiling new textbooks and teaching aids. The authors conclude that on the whole the existing textbooks are aimed at the formation of language knowledge and development of speaking skills, but their drawback is that they are not sufficiently aimed at the formation of professional skills and development of personal competencies essential for the future teacher.
\end{abstract}

\section{Introduction}

The need for renovation and perfection of the process of practical training of future teachers in the conditions of new Federal State Educational Standard (FSES) of Higher Education, 3++ introduction is extremely important for pedagogical education. It is accounted for the fact that educational standards are built on the basis of professional standards, which is reflected in the content of universal, general professional and professional competencies.

At the present stage, the leading countries of the world attach special importance to education in the formation and accumulation of human capital [1]. Training future teachers of foreign languages presupposes the formation of a teacher who is ready to work in constantly changing socio-economic conditions and quickly adapt to educational innovations, to the search of non-standard solutions, ways of self-perfection and application of creative approaches to his / her work [2], who is culturally fluent, and this quality determines the teacher's language personality and linguistic identity and makes them relevant in both domestic and foreign labor market [3].

The achievement of the above goals in the system of linguistic education is realized through a textbook, which is the main means of teaching-learning process. "A textbook for higher education plays a special role, since it participates in a complex multidimensional process of forming the students' professional personality while their success in the professional sphere depends on its quality" [4].
A lot of attempts have been made to compile a textbook for teaching students Chinese at the initial level regardless of the number of hours and major of courses of study providing for maximum efficiency of teachinglearning process [5]. In spite of the fact nowadays we have a considerable experience in compiling university textbooks for European languages, the problem of compiling a University textbook for training teachers of Chinese requires special attention. As Indira $R$. Abdulmyanova mentions, "The catalogues of Russian educational and library platforms contain a large number of textbooks on foreign language for future specialists in various fields (lawyers, civil servants, specialists in the field of tourism, economists, journalists, technologists, etc.). But there are no textbooks containing an indication of being written for future foreign language teachers in their title" [4].

\section{Problem statement}

As we can see, today the problem of creating a textbook (for higher education) which will meet the requirements of FSES of Higher Education for future teachers of Chinese still exists and is not paid enough attention to. In this article the authors presented analysis and evaluation of contents of the existing textbooks of Chinese which let them find out some disadvantages and work out some ways of solving the problem. 


\section{Purpose of the study}

The purpose of the present research is to state the requirements for the Chinese language textbook content on the basis of evaluation and analysis of the existing textbooks.

\section{Research methods}

The following methods of research have been used in accordance with its purpose: analysis of psychological, pedagogical and methodical literature; organization and evaluation of teaching-studying process and how it is put into practice in this field, how efficient the textbook is for training teachers of Chinese.

\section{Results and discussion}

As far as we understand, the problem raised in the article can be accounted for reasons of systematic character, such as:

1. Absence of normative documents to determine the key regulations of teaching the Chinese language.

At present, the main normative point for university teachers is Federal State Educational Standard of Higher Education which suggests general requirements for the conditions, structure and results of mastering basic educational syllabi and curricula. Expressing the social order of the state in relation to the quality of professional training of university graduates, FSES, nevertheless, doesn't raise the problem of formalizing the requirements for syllabi and curricula in this or that subject. So far, they haven't formulated the generally accepted system of evaluating the level of students' knowledge of Chinese, as is the case with the European system CEFR. The latest version of International curriculum for the Chinese language education (2014) adapted to the international qualification exam in the Chinese language doesn't find its place within generally accepted methodological frames regulating the methodological provision of the subject, besides, the HSK system itself is in the process of permanent reform. The present situation contributes to indefiniteness, both from the point of veiw of the content of syllabus (the approximate list of topics, lexico-grammatical minimum, etc.), and the demarcation of the levels of teaching Chinese, which is a serious obstacle to compiling and perfection of textbooks and teaching aids.

2. Poor methodological training of the greater part of teachers of Chinese for Russia's Universities. By now we have acquired a considerable experience in research and systematization of linguo-cultural peculiarities of the Chinese language, some scientific schools on its research have appeared, but methods of teaching Chinese as a foreign language are poorly presented. So, for July 2021, the inquiry «the Chinese language » presented the following information at the Dissercat platform - 4812 dissertations including 297 defended on pedagogical sciences : 13.00.01. (General Pedagogy, History of Pedagogy and Education) - 84,
13.00.02 (Theory and Methods of Teaching and Upbringing (different fields and levels of education) 164, 13.00.08 (Theory and Methods of Professional Education) - 49 (only one of them is doctoral dissertation by T.L. Guruleva). As a rule, basic education of higher schools teachers of Chinese directly correlates with the Chinese language (philology, area studies, Asian and African studies), but it is seldom directly related to teaching methods of a foreign language. According to T.L. Guruleva [6], the root of the problem of a lack of teachers is the political processes that are underway both in Russia and China. She writes that mass involvement of students in studying Chinese requires a mass number of high school teachers. But the process of qualified teachers training couldn't keep up with the new requirements of the society. The current situation demonstrates an acute lack of professional teachers, which is negatively reflected both on the quality of training specialists in the Chinese language and the development of teaching methods for the subject.

3. Poor integration into the international space. At the same time, it should be mentioned that in the domestic pedagogical science the theory of a textbook was worked out, the basic requirements for the textbook were defined, the specific characteristics of a foreign language textbook were considered and offered. Such authors as E.I. Bim [7], A.A. Mirolyubov [8], G.L. Vitlin [9], I.V. Rakhmanov [10], L. Götze [11], G. Neuner [12] and some others consider the main aspects of a textbook as a didactic model of education, describe the requirements for selection of the content of educational material whose components are: themes, communication situations, language and speech material, process aspect, exercises. Problems of integration of country study and socio-cultural aspects are introduced in all components of educational process [13]. It is important to orient the textbook at the personality of the students since they are active participants of teaching-learning process [14]. Modern research of foreign language textbooks is based on their three major functions: representation, interaction, learning [15], [16], thereby "expanding our understanding of the textbook as an educational, cultural, pedagogical and ideological site for research" [15]. All the authors agree that the textbook should to a maximum degree alleviate the process of mastering a foregn language, it must be interesting, attractive in form and content, convenient and easy-to-use.

We consider it expedient to have a textbook in the Chinese language for future teachers aimed at the initial stage of teaching which lays the foundation for their professional specialization.

To analyze the existing experience we have chosen the textbooks of practical Chinese for beginners which are most frequently used in our country's universities. The first three textbooks have a signature stamp ERO (Education Review Office) and, as a rule, are included in the list of basic subjects of most universities training specialists for teaching Chinese: «Practical Course of Chinese» edited by A.F. Kondrshevsky (PCC), «Foundations of the Chinese Language. Introductory Course» and «Foundations of the Chinese Language. Basic Course» by T.P. Zadoenko and Huang Shuying 
(FCL), «Textbook in the Chinese Language. New Practical Course» by A.M. Karapetiants, Tan Aoshuang (TCL). We analyze the latest textbook - «The New Practical Course of Chinese» edited by Lyu Xun (NPCC) as a classical textbook of practical Chinese. It was published in Bejing, acknowledged all over the world and translated into Russian.

The initial appraisal of the form of the textbooks selected as objects for research from the formal point of veiw enables us to point out the following peculiarities:

1) Quite a long history of existence and usage.

For example, FCL is the textbook which was published in the USSR as a mass edition, the first edition was published in 1983 and it is still widely used at Universities at present. The other three go back to 1986 and continue the basic content of «Practical Course of Chinese» edited by Lyu Xun. The most modern textbooks in the list above are PCC and NPCC, which were republished some time ago. But, although a great deal of work was done by the authors to adapt and activate the material (the content) of the published textbooks, it's quite obvious that the speech material that goes back to the 80 -s of the previous century does not reflect the modern society realties and requires thorough analysis.

2) Universal target audience.

In the foreword of the analyzed textbooks the authors point out that they are aimed at university students whose speciality is Asian and African Studies, they don't specify in the program (FCL, PCC, NPCC). Thus, those textbooks claim their universality, NPCC, which is intended for high school and secondary students, irrespective of the country of origin, has the widest spectrum of target audience. Nevertheless, as T.L. Guruleva [5] mentions, in spite of authencity of the speech material and good translation of this textbook into Russian, it basically presents an intercultural dialogue with a person of some universal Western culture but not the person of cultural identity. Moreover, there exist quite significant differences both in linguistic and methodological and linguo-didactic traditions and innovations of national and Chinese systems of education, that is why using Chinese textbooks for Russian students, their methods and ways of teaching can't always be effective and successful [6]. The other three textbooks positively differ from the one described by the fact that they are supported with the Russian language and Russian reality.

3) Partial Completeness.

Of all the textbooks analyzed, NPCC can be regarded as a comprehensive and valuable educationalmethodical complex, for it includes audio and video supplements, a workbook and a teacher's book. But absolute advantage of all the textbooks analyzed is their linguaphone provision voiced by native speakers, which contributes to mastering the language of the sociocultural medium different from the country of the language studied.

Having analyzed the content of the selected textbooks we arrive at the following conclusions:

1) All the textbooks analyzed are built on similar logic: the initial stage of education is the introductory phonetic course which is quite different in volume in the 4 subjects of research (from two lessons in NPCC to one part in FCL). The form of basic texts is presented in a similar way - in the first 15-20 lessons (TCL, NPCC) the texts are duplicated by pinyin, futher on only their tone drawing is preserved. Nevertheless, the principle «oral speech first » is preserved only in FCL textbook, only this textbook offers oral speech exercises prior to texts. The other textbooks analyzed violate the principle of complication in teaching characters: from the first lesson on, the vocabulary is doubled by characters, which, in its turn, demands that teachers have to take some additional measures to organize the process of mastering elementary skills of using characters. Thus, of all the textbooks we have analyzed, FCL is the only one to give complete and reasonable theoretical foundations of phonetics and calligraphy rules. Nevertheless, superfluous theoretical material results in disbalance of speech and language material, which complicates its usage as a universal textbook for teaching Chinese, but it can be a good theoretical basis that supplements the selected Practical Course textbook.

2) An absolute and indispectable advantage of the textbooks compiled by Russian authors (PCC, FCL, TCL) is profound analysis of grammar material, its adaptation to Russian speaking students, agreement with the traditions of Russia 's Universities. It should be specially noted that the TCL textbook authors not only widely use comparative approach to teaching Chinese and consider the realities of the country, they accentuate problems of conveying meanings and definite speech patterns (tendencies). PCC stands out from the other textbooks by detailed examples and visual aids in delivering grammar material. Nevertheless, these textbooks' disadvantage is their weak communicative aspect of grammar exercises, and poor presentation of functional correlation of grammar and speech material of the two languages.

3) On the whole, the lexical material of the textbooks we have analyzed corresponds to the age peculiarities of university students, but their content sometimes insufficiently reflects the peculiarities of the modern society that undergo considerable transformations. We agree with M.Ya. Beilina [17], who considers that since the main source of information in the textbook is the text, the work with this textbook must begin with proper selection and sequence of its texts. Selection of texts must be based not only on their themes, but also their educational value. Proceeding from this idea, it should be noted that the speech material of the textbooks analyzed sometimes doesn 't have communicative value, the texts may not fully reflect the present-day students' interests, which doesn't contribute to motivation of oral presentation of the material. Besides, it's not always possible to introduce the vocabulary offered in presentation of the topic discussed.

4) The exercises in the textbooks analyzed are overloaded, but at the same time it allows the teacher to select the necessary minimum for formation of firm skills of hearing, pronunciation, rythm and intonation, grammar and vocabulary. But the exercises aimed at speaking (speech practice) are presented by substitution 
exercises, situation-building exercises, which are rather partially speaking exercises and seldom contribute to speech development. At the same time, formation of speaking skills requires specification in the formulation of situational tasks. Grammar and vocabulary of the topics are activated mainly by means of translation exercises, which disagrees with the aims and tasks of contemporary requiremnents for foreign language teaching. Unfortunately, listening comprehension exercises are not included in the textbooks, but their importance for the development of speech must not be underestimated. Although university teachers of Chinese in our country have published a lot of supplementary materials to form different competencies, teachers have to spend much time and efforts in search of necessary material, and a new integrated textbook could "provide them with guidance and support and reduce the amount of time they require for preparation. Textbooks also help students to be more autonomous in their learning" [18].

5) Learning a forein language pupils and students become aware of their own culture by comparing it with another country's culture. But our country's culture is not included in the didactic content of the textbooks analyzed, and our teachers have to search for supplementary material for classes. Besides, the culture of China is also poorly presented in the textbooks. The textbooks present a separate block of culture in the form of notes to the text, but the text itself doesn't raise any problems that can encourage students to speak. It may lead to their growing interest both in the study of the country and the Chinese language. But the texts mainly describe the life of foreign students in China. They are aimed at bringing up students in the spirit of benevolence to people, responsibility, curiosity, but at the same time they pay no attention to bringing up their sense of patriotism.

\section{Conclusion}

Thus, the analysis of textbooks for teaching Chinese lets us propose some requirements to the content of such textbooks for future teachers of Chinese:

-selection of the content for the Chinese Language textbook requires the principals of necessity and sufficiency for realization of teaching goals in the University subject, it also requires understanding of content as a whole as well as its separate parts;

- the content of the textbook must also include specially selected volume of knowledge and understanding of its regularities for the future sphere of a teacher's professional activity;

- the content must take into consideration the age and individual peculiarities of the students, their intellectual level, the optimal conditions for independent work, various kinds of the teaching-learning process;

- the work with the textbook content must provide conditions for comparing facts of two cultures, two world pictures, two systems of value priorities, which will contribute to the formation of intercultural competence as a component of professional competence of the future teacher of Chinese.
So, the analysis of university textbooks for teaching Chinese shows that, on the whole, they contribute to the formation of language and speech skills and to a great extent they are aimed to impart knowledge, but they must prepare students to comprehensive qualified work after graduation, forming personally, professionally and socially significant competencies and readiness to develop and grow continuously throughout their professional life.

\section{References}

1. O.V. Zinina, O.I. Antamoshkina, J. A. Olentsova, Methodology for Evaluating the Effectiveness of Investments in Distance Educational Services / Proceedings of the 35th International Business Information Management Association Conference (IBIMA), 3681-3689 (2020)

2. A.L. Berdichevsky, E.G. Tareva, N.V. Yazikova, Professional Diagram of a modern language teacher, 48, 48 (2021)

3. K.M. Levitan, M.A. Yugova, A textbook of Foreign Language for Specific Purposes as a Means of Developing Students' Innovative Linguistic Identity / Language and Culture, 44, 248-260 (2018)

4. I. R. Abdulmyanova, A foreign language textbook as a tool for professionalizing a future linguist's language training / Textbook: Focus on Students' National Identity, 4, 1-13 (2021)

5. T.L. Guruleva, A.V. Makarov, Higher Linguistic Education in Russia: Some Problems of Sinologist's Training In Higher Educational Institutions / Higher Education in Russia, 8-9, 88-94 (2013)

6. T.L. Guruleva, Status and Problems of Developing Educational Resources in the Chinese Language in Higher School / Higher Education in Russia, 5, 50-58 (2018)

7. I.L. Bim, Some starting positions for a foreign language textbook theory / Foreign Languages in School, 3, 3-8 (2002)

8. A.A. Mirolyubov, The history of Russian methodology of teaching foreign languages, 448 (2002)

9. G.L. Vitlin, Theoretical and methodological foundations of the first foreign language textbooks for high schools / Foreign languages in school, 3, 4550 (2007)

10.I.V. Rakhmanov, Some theoretical problems of teaching foreign languages in middle school / General methodology of teaching foreign languages, 9-20 (1991)

11. Götze L. Fünf Lehrwerkgenerationen. Kast/Neuner, 1994. S. 29-30. [L.Götze Fünf Lehrwerkgenerationen / Zur Analyse, Begutachtung und Entwicklung von Lehrwerken für den fremdsprachlichen Deutschunterricht, 2, 29-30 (1994)]

12. G. Neuner, Lehrwerke / Handbuch Fremdsprachenunterricht, 4, 399-402 (2003)

13. N.A. Gorlova, Evaluation of the quality and effectiveness of teaching materials in foreign 
languages / Foreign Languages in School, 8, 19-27 (2005)

14.E.S. Babykova, Why should Russian textbooks be used when teaching German / Foreign Languages in School, 1, 38-39 (2000)

15. G. Canale, The language textbook: representation, interaction and learning / Language, Culture and Curriculum, 2, 113-118 (2021)

16. C. Weninger, Multimodality in critical language textbook analysis / Language, Culture and Curriculum, 2, 133-146 (2021)
17. M.Ya. Beilina, Structural features of a textbook directed to the development of literature reading skills for professional purposes / Foreign Languages in Higher School, 4, 3-10 (1968)

18. B. Lopez-Medina, Developing a CLIL Textbook Evaluation Checklist / Latin American Journal of Content and Language Integrated Learning, 9, 159173 (2016) 